\title{
Technology for Location, Analysis and Interpretation of Magnetic Alterations as Precursors of Seismic Phenomena Update
}

\author{
Raymond Rosa Ávila*, Rafael A. López Ramos, Justo Gonzalez Díaz \\ Particles Observatory of Puerto Rico, Caribbean University of Puerto Rico
}

\section{Keywords}

Signal precursors, Magnetometers, Earth's magnetic field,

Earthquakes,

Magnetic alterations,

Disturbances.

\begin{abstract}
To date, several studies have shown that the Earth's magnetic field suffers alterations at the local geographical location before an earthquake occur. Its study demonstrates that the Earth's magnetic alterations at specific local geographical zone, is a local seismic precursor alerting a proximity of an earthquake with a margin of error of approximately $10 \%$. The electromagnetic noise from background is very confusing, but that reason was necessary to identify these electromagnetic signal precursors by filtering a large amount of noise. To isolate the electromagnetic noise, was implemented a Magnetic North deflection detection in Smart Phones Magnetometers. Using it technology, was developed a mathematical algorithm that work in combination with the Smart Phones magnetometers. This research was based using in reference the study carried out by the Department of Physics of the Faculty of Physical Sciences and Mathematics (FCFM) of the University of Chile directed by Cordado, 2018[1], in the paper called "Latitudinal variation rate of geomagnetic cutoff rigidity in the active Chilean convergent margin".
\end{abstract}

\section{Introduction}

In principle, this study is based on the early detection of seismic events for highly seismic zones and where there are tectonic faults in their vicinity. It is proposed as a theory to prove that before an earthquake event occurs in a seismic zone, a series of disturbances occur in the earth's magnetic field. Currently there are research works that have managed to prove the existence of such a seismic precursor (Cordaro, 2018) [1], but there is currently no way to estimate the place, magnitude, and time in which the event may occur for a highly seismic zone.

According to Professor Friedemann Freund of NASA, he expressed in a press release published in 2001 (Freund, NASA, 2001) [2], that the Earth's Magnetic Field shows alterations produced at the local level, and that it is highly probable that soon it would be possible to interpret the signals with technological equipment. electrics that our restless planet emits when the earth's crust breaks with devastating force.

The study and observations of the fluctuations in Earth's magnetic field behavior was performed for Puerto Rico, its fluctuations were identified as an earthquakes precursor. The observed precursor is based on the study carried out by Friedemann Freund presented in his Publication (Freund, Pre-earthquake signals: Underlying physical processes, 2011) [3]. During the Research process of this Study, using the magnetometer provided in smart phones, it allows, in a vector way, to identify the area where this event could manifest itself, its magnitude and the approximate time in which a seismic event could occur. Magnetic alterations are produced when, at the beginning of a fracture process in the rocks located in the tectonic faults, they confront an increase in pressure and friction due to the contact between the said tectonic plates, as explained by Dr. Freund in his publication (Freund, 2011) [3].

With the available technology, it is possible to study in more detail the behavior of the tectonic plates of a geographical area, which is why with this study, not only the alterations of the magnetic field have been observed, but also have been identified as a real seismic precursor.

This is because it is bases on vectors orientation that it is possible to identify the proximity of an earthquake event with a margin of error of approximately $10 \%$. It is true that on our planet there is a lot of electromagnetic noise that can be very confusing. However, this research has managed to identify in a serious way that within said electromagnetic noises it is possible to identify the alteration of the earth's magnetic field by means of a vector deviation which has been identified as a seismic precursor by means of a process of filtering electromagnetic noise by means of the implement of a compass to measure geomagnetic disturbance.

With the implementation of smart phones, it has been possible to increase the study by means of an application in the Android operating system that allows downloading and installing a data collector and generating a local analysis of the seismic trend for a specific geographical area.

\section{Methodology}

\subsection{Data Collection through Mobile Application}

To carry out this research, it was necessary to develop an application on the Android programming platform. This environment made it possible to use the magnetometer provided in today's smart phones. The application required the development of a programming algorithm with which the fluctuations of the magnetic field for the study area are monitored in real time. With the application it was possible to obtain a data record of which, by observation, they allow to study the local magnetic field for different points of the Island of Puerto Rico. Being an application for smart phones, a call was made to a group of volunteers and collaborators from the community to install the program and be able to collect data in different areas of the Island of Puerto Rico. Through the observation of the data of the magnetic field obtained by the different smartphones of the group of volunteers, a network of daily sampling data was developed. Each 
volunteer in the group places the smartphone on a flat surface and, using a compass, orients it towards the magnetic north. This allows that when the phone is just oriented towards the magnetic north the magnetometer is aligned within a Cartesian plane. Once the data obtained is aligned, they are recorded with a graphic reference to then study the data obtained from each device through a central data bank that receives the information from the collected sample.

\subsection{Earthquake Detection Process}

Through the information obtained by the application developed and installed in various smart phones, data were obtained that allowed us to observe and study the fluctuations in the magnetic field locally for Puerto Rico. It was possible to verify that during a time before an earthquake occurs, a geomagnetic alteration occurs locally. This geomagnetic alteration occurs because of the initial process in the process of fracturing the rocks and minerals that make up the interaction zones between the tectonic plates of the studied area.

This anomalous behavior can be observed in compasses, indicating that when an area is prone to a major seismic event, it tends to have marked deflections. This occurs because the needle that marks the magnetic north begins to deflect in the direction of the zone in process of fracture between tectonic plates where the future seismic even could occur. This anomalous behavior is also verified in the readings obtained by the application running on smart mobile phone devices.

Once the data are registered in the central data bank, they are collected by means of numerical values of the magnetic field referred to the three main axes $x, y$, and $z$. These values begin to have abnormal values in the three reference axes, which allows us to coordinate where is the place where the event could occur and its possible magnitude.

The magnetometer provided by smart phones allows the information to be recorded continuously for the study area, allowing to compare the values obtained through an analysis algorithm that contains a series of mathematical formulas to determine the possible magnitude, location, and approximate time for the possible future seismic event The application collects data on the value of the $\mathrm{x}, \mathrm{y}$, and $\mathrm{z}$ axes, allowing it to be studied as a seismic precursor, determining the exact moment of the magnetic variation, thus allowing to forecast the future seismic event.

\subsection{Mathematical Equations Implemented in the Algorithm of the Smart Phone Application}

The programming algorithm for the mobile application was developed with a series of empirical formulas that were developed through this study. The empirical formula to determine the initial vectorial estimated magnitude given by Eq. (1), Eq. (2) and Eq. (3) for the possible future seismic event was developed as part of this research work as a function of $\mathrm{X}, \mathrm{Y}, \mathrm{Z}$ and cte.

$$
\begin{aligned}
& M x=\frac{X}{c t e} \\
& M y=\frac{Y}{c t e} \\
& M z=\frac{Z}{c t e}
\end{aligned}
$$

Where $\mathrm{X}, \mathrm{Y}$, and $\mathrm{Z}$ are the magnetic field at the magnetic field anomaly detection. The Constant cte value depends on the geological composition of the rocks and their characteristic minerals of each zone in the local tectonic fault closest to the magnetometer. This is important since the geological and mineral composition of the earth's crust where the tectonic plates act, influences the form of energy propagation. Based on the studies carried out in this investigation, it was determined by experimentation that the value of the constant cte is approximately 32 for Puerto Rico Geographical location.

For the final estimated mathematical computation of the prognosticated magnitude $\mathrm{M}$ given by Eq. (4) is required to select the maximum ( $\left.\mathrm{M}_{\max }\right)$ obtained value of $\mathrm{Mx}, \mathrm{My}$, and $\mathrm{Mz}$. It is necessary to mention that $M_{\max }$ will be the magnitude determined for the area where the mobile phone device is located.

$$
M=M_{\max }
$$

Therefore, it does not represent the total magnitude of the earthquake at its initial epicenter. To determine the estimated magnitude of the possible earthquake based on its estimated epicenter, the implementation of more mobile phone devices located in different areas is required to perform a triangulation based on the position of the possible epicenter of the predicted earthquake event. Based on observation and experimental data, it has been found that the magnitude $\mathbf{M}_{\max }$ determined by the empirical formula of Eq. (4) varies depending on the location of the mobile phone. Experimentally it has been observed that on average the real magnitude of the earthquake predicted by the mobile application will increase at the rate of 0.008 Mw per kilometer approximately.

To determine the approximate time in which the seismic event predicted by the mobile application could occur, an empirical formula for time was developed experimentally using Eq. (5).

$$
\text { Time }=\frac{L}{V p}
$$

\section{$\mathrm{L}=0.162$ (Puerto Rico Geographical localization)}

The estimated time until the possible seismic event is determined in estimated hours. To determine the time, it is required to obtain through experimental data the value of the constant $\mathrm{L}$. The constant $\mathrm{L}$ depends on the geographical location of the study, this constant I for Puerto Rico has an approximate value of 0.162 . Finally, the location constant $\mathrm{L}$ is divided by the translation speed $\mathrm{Vp}$, experimentally it is estimated for the fault zone between the tectonic plates located in the perimeter of the geographic zone under study. The speed variable is determined in $\mathrm{mm} /$ hour for mathematical calculation. Fig. 1 shows the velocity map Vp in one-year tectonic Plates displacement per year for the zone of interaction between tectonic plates where Puerto Rico is geographically located.

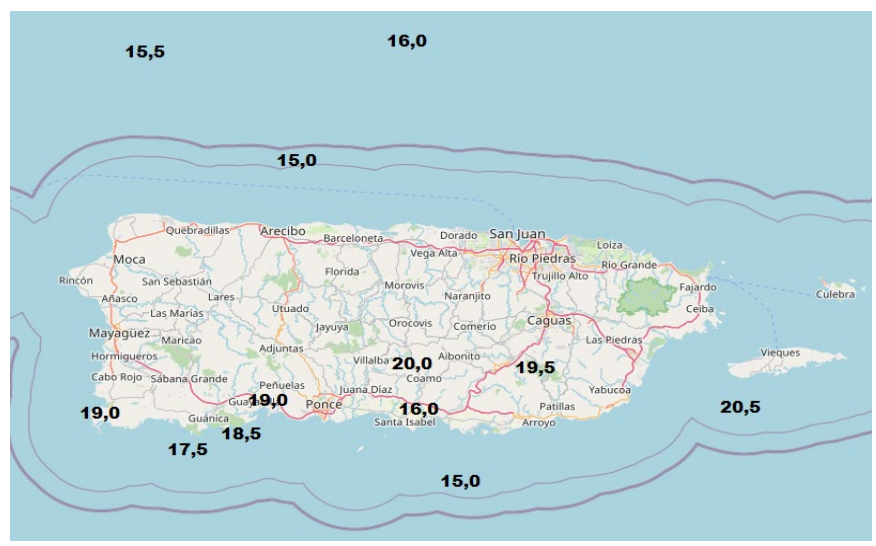

Figure 1. Estimated Vp Velocity in $\mathrm{mm} /$ year of the Tectonic Plates in the Puerto Rico Zone

The location of the possible seismic event is estimated by observing the momentary deflection of the earth's magnetic field, just as the earth's magnetic field is observed when using a compass. When a significant anomaly occurs in the earth's magnetic field, it has been observed that it is possible to estimate the orientation of the possible hypocenter of the predicted seismic event based on the momentary signal rotation with respect to the real magnetic north. With the application developed for smartphones it is possible to obtain the data from the magnetometer in the $\mathrm{x}, \mathrm{y}$, and $\mathrm{z}$ coordinates. This information is mathematically transformed to rotation and thus the angle of rotation towards which the earth's magnetic north deflected is momentarily deflected with respect to the true magnetic north. As more mobile phones are implemented for data collection with the developed application, it is possible through triangulation of rotations obtain a more accurate estimate of the place where the possible seismic event could occur. 


\section{Data Collection and Results Analysis}

With the data obtained by smart phones, the captured magnetic field signals allow us to mathematically estimate the magnitude according to Eq. (1) and the time according to Eq. (2) until the possible manifestation of the seismic event. The Table 1 shows the data collected by the mobile devices used for this data collection experiment. Then the data of the magnetic field are shown in microtesla as time passes in Spanish reference local time. With the data, the rotation data due to the momentary deflection of the magnetic north are also obtained. With the data collected the algorithm of smartphone application forecast of the possible magnitude and estimated time of the seismic event is obtained.

In Table 2 the results obtained from the experiment can be observed referring to the detection time. The day and time forecast of the forecasted seismic event is indicated and followed by the record of the events handled with their corresponding magnitude, rotation, and distance in kilometers with respect to the monitoring device used in this experiment.

Table 1. Data Collected by Smart Phones and Prognosticated Earthquake Event

\begin{tabular}{|c|c|c|c|c|c|c|c|}
\hline $\begin{array}{l}\text { DETECTION } \\
\text { TIME } \\
\text { (Spain) }\end{array}$ & $\begin{array}{c}\text { Phone } \\
\text { Device } \\
\text { Zone }\end{array}$ & $\underset{(\mu \mathrm{T})}{\mathrm{X}}$ & $\begin{array}{c}\mathrm{Y} \\
(\mu \mathrm{T})\end{array}$ & $\begin{array}{c}z \\
(\mu \mathrm{T})\end{array}$ & $\begin{array}{l}\text { Degrees of } \\
\text { Deflection }\end{array}$ & $\begin{array}{l}\text { Predicted } \\
\text { Magnitude } \\
(\mathrm{Mw})\end{array}$ & $\begin{array}{c}\text { Estimate } \\
\text { Time } \\
(\mathrm{Hr})\end{array}$ \\
\hline $\begin{array}{c}1 / 03 / 2021 \\
22: 39: 04\end{array}$ & TOA N1 & 0 & 76 & 76 & 280 & 2.6 & 90.0 \\
\hline $\begin{array}{c}13 / 03 / 2021 \\
23: 22: 49\end{array}$ & TOA & 1 & 76 & 3 & 360 & 2.6 & 95.3 \\
\hline $\begin{array}{c}15 / 03 / 2021 \\
18: 37: 02\end{array}$ & TOA N1 & 1 & 70 & 118 & 359 & 2.4 & 95.3 \\
\hline $\begin{array}{c}22 / 03 / 2021 \\
20: 20: 01\end{array}$ & TOA N1 & 1 & 63 & 91 & 295 & 2.0 & 73.6 \\
\hline $\begin{array}{c}24 / 03 / 2021 \\
14: 33: 51\end{array}$ & TOA N1 & 3 & 87 & 100 & 70 & 2.7 & 70.4 \\
\hline $\begin{array}{c}27 / 03 / 2021 \\
3: 35: 21\end{array}$ & TOA N1 & 1 & 53 & 35 & 340 & 1.7 & 70.4 \\
\hline $\begin{array}{c}2 / 04 / 2021 \\
17: 24: 10\end{array}$ & $\begin{array}{l}\text { PONCE } \\
\mathrm{N}\end{array}$ & 1 & 73 & 4 & 360 & 2.3 & 81.0 \\
\hline $\begin{array}{c}13 / 04 / 2021 \\
15: 57: 04\end{array}$ & TOA 2 & 1 & 61 & 75 & 75 & 1.9 & 73.6 \\
\hline $\begin{array}{c}17 / 04 / 2021 \\
22: 09: 12\end{array}$ & TOA 2 & 2 & 62 & 82 & 120 & 1.9 & 77.1 \\
\hline $\begin{array}{c}24 / 04 / 2021 \\
17: 49: 55\end{array}$ & PONCE & 63 & 173 & 18 & 155 & 5.4 & 77.1 \\
\hline $\begin{array}{c}24 / 04 / 2021 \\
22: 54: 54\end{array}$ & PONCE & 3 & 171 & 21 & 168 & 5.3 & 77.1 \\
\hline $\begin{array}{c}3 / 05 / 2021 \\
0: 15: 43\end{array}$ & $\begin{array}{l}\text { SAN } \\
\text { SEBAS- } \\
\text { TIÁN }\end{array}$ & 158 & 323 & 13 & 119 & 10.1 & 85.3 \\
\hline $\begin{array}{c}19 / 05 / 2021 \\
2: 53: 15\end{array}$ & TOA 2 & 26 & 69 & 2 & 67 & 2.2 & 90.0 \\
\hline $\begin{array}{c}25 / 05 / 2021 \\
19: 52: 52\end{array}$ & $\begin{array}{l}\text { SANTA } \\
\text { ISABEL }\end{array}$ & 95 & 80 & 45 & 50 & 2.5 & 73.6 \\
\hline $\begin{array}{c}25 / 05 / 2021 \\
19: 30: 54\end{array}$ & $\begin{array}{l}\text { SANTA } \\
\text { ISABEL }\end{array}$ & 67 & 49 & 51 & 18 & 1.5 & 95.3 \\
\hline
\end{tabular}

During the days of April 24, 2021, an important anomaly was registered in the magnetic field captured by one of the mobile devices. This anomaly was presented in bold text for Tables 1 and 2. The data was collected by the mobile device located in the location of Ponce at south side of the Puerto Rico Island. The Figure 2 shows the graph generated by the central data collection bank for all the devices in operation during that day.

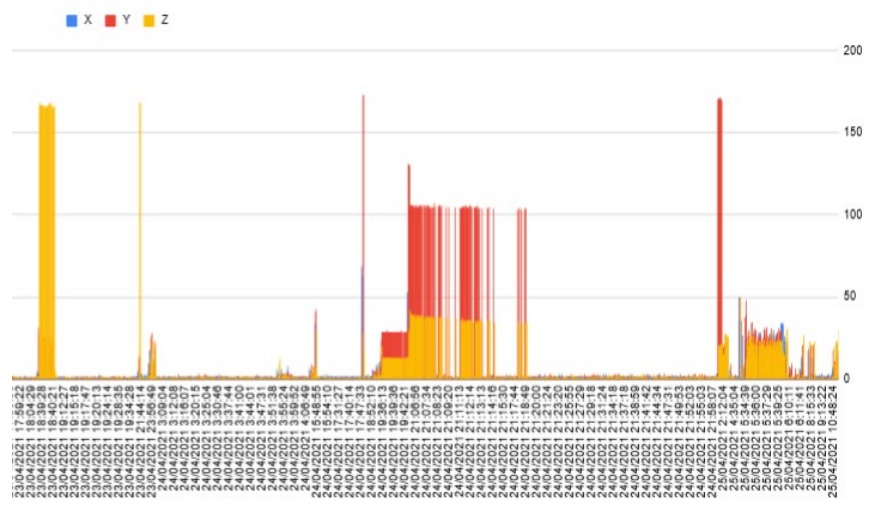

Figure 2. Graph of the Data Recorded During the Days of Anomaly Occurred on April 24, 2021, at Ponce smartphone

Table 2. Estimated Event Date, Dates of occurrence of events, Magnitude of Event and Distance

\begin{tabular}{|c|c|c|c|c|c|}
\hline $\begin{array}{l}\text { DETECTION } \\
\text { TIME } \\
\text { (Spain) }\end{array}$ & $\begin{array}{l}\text { Predicted } \\
\text { Time to } \\
\text { Event }\end{array}$ & $\begin{array}{l}\text { Real Time to } \\
\text { Event }\end{array}$ & $\begin{array}{l}\text { Real Magnitude } \\
(\mathrm{Mw})\end{array}$ & $\begin{array}{c}\text { Real } \\
\text { Rotation }\end{array}$ & $\begin{array}{c}\text { Real } \\
\text { Distance } \\
(\mathrm{km})\end{array}$ \\
\hline $\begin{array}{c}1 / 03 / 2021 \\
22: 39: 04\end{array}$ & $\begin{array}{c}5 / 03 / 2021 \\
16: 39: 04\end{array}$ & $\begin{array}{c}05-03-2021 \\
19: 28: 52\end{array}$ & 3.0 & 200 & 51 \\
\hline $\begin{array}{c}13 / 03 / 2021 \\
23: 22: 49\end{array}$ & $\begin{array}{c}17 / 03 / 2021 \\
22: 40: 28\end{array}$ & $\begin{array}{c}17-03-2021 \\
21: 43: 28\end{array}$ & 3.4 & 280 & 118 \\
\hline $\begin{array}{c}15 / 03 / 2021 \\
18: 37: 02\end{array}$ & $\begin{array}{c}19 / 03 / 2021 \\
17: 54: 41\end{array}$ & $\begin{array}{c}19-03-2021 \\
20: 37: 13\end{array}$ & 3.8 & 260 & 70 \\
\hline $\begin{array}{c}22 / 03 / 2021 \\
20: 20: 01\end{array}$ & $\begin{array}{c}25 / 03 / 2021 \\
21: 58: 12\end{array}$ & $\begin{array}{c}25-03-2021 \\
22: 18: 34\end{array}$ & 2.5 & 290 & 40 \\
\hline $\begin{array}{c}24 / 03 / 2021 \\
14: 33: 51\end{array}$ & $\begin{array}{c}27 / 03 / 2021 \\
12: 59: 57\end{array}$ & $\begin{array}{c}27-03-2021 \\
12: 13: 33\end{array}$ & 3.2 & 340 & 84 \\
\hline $\begin{array}{c}27 / 03 / 2021 \\
3: 35: 21\end{array}$ & $\begin{array}{c}30 / 03 / 2021 \\
2: 01: 26\end{array}$ & $\begin{array}{c}30 / 03 / 2021 \\
3: 07: 23\end{array}$ & 3.8 & 120 & 72 \\
\hline $\begin{array}{c}2 / 04 / 2021 \\
17: 24: 10\end{array}$ & $\begin{array}{c}6 / 04 / 2021 \\
2: 24: 10\end{array}$ & $\begin{array}{c}6 / 04 / 2021 \\
2: 40: 40\end{array}$ & 2.5 & 260 & 72 \\
\hline $\begin{array}{c}13 / 04 / 2021 \\
15: 57: 04\end{array}$ & $\begin{array}{c}16 / 04 / 2021 \\
17: 35: 15\end{array}$ & $\begin{array}{c}16 / 04 / 2021 \\
19: 10: 05\end{array}$ & 2.0 & 150 & 35 \\
\hline $\begin{array}{c}17 / 04 / 2021 \\
22: 09: 12\end{array}$ & $\begin{array}{c}21 / 04 / 2021 \\
3: 17: 46\end{array}$ & $\begin{array}{c}21 / 04 / 2021 \\
3: 07: 25\end{array}$ & 2.8 & 200 & 60 \\
\hline $\begin{array}{c}24 / 04 / 2021 \\
17: 49: 55\end{array}$ & $\begin{array}{c}27 / 04 / 2021 \\
22: 58: 29\end{array}$ & $\begin{array}{c}27 / 04 / 2021 \\
23: 23: 23\end{array}$ & $2.6-2$ & 270 & 65 \\
\hline $\begin{array}{c}24 / 04 / 2021 \\
22: 54: 54\end{array}$ & $\begin{array}{c}28 / 04 / 2021 \\
4: 03: 28\end{array}$ & $\begin{array}{c}28 / 04 / 2021 \\
4: 24: 00\end{array}$ & $2.9,2.9$ & 260 & 115 \\
\hline $\begin{array}{c}3 / 05 / 2021 \\
0: 15: 43\end{array}$ & $\begin{array}{c}6 / 05 / 2021 \\
13: 31: 30\end{array}$ & $\begin{array}{c}\text { 6/05/2021 } \\
13: 01: 20\end{array}$ & $2.7,2.6,3.4 \ldots$ & 150 & 100 \\
\hline $\begin{array}{c}19 / 05 / 2021 \\
2: 53: 15\end{array}$ & $\begin{array}{c}22 / 05 / 2021 \\
20: 53: 15\end{array}$ & $\begin{array}{c}22-05-2021 \\
23: 49: 35\end{array}$ & 3.2 & 330 & 84 \\
\hline $\begin{array}{c}25 / 05 / 2021 \\
19: 52: 52\end{array}$ & $\begin{array}{c}\text { 28/05/2021 } \\
\text { 21:31:03 }\end{array}$ & $\begin{array}{c}28-05-2021 \\
20: 48: 19\end{array}$ & 2.9 & 150 & 30 \\
\hline $\begin{array}{c}25 / 05 / 2021 \\
19: 30: 54\end{array}$ & $\begin{array}{c}29 / 05 / 2021 \\
18: 48: 33\end{array}$ & $\begin{array}{c}29-05-2021 \\
17: 33: 00\end{array}$ & 2.6 & 270 & 50 \\
\hline
\end{tabular}

The Table 1 shows that the predicted magnitude was 5.4 and $5.3 \mathrm{Mw}$ while the actual magnitude was divided into four events between 2 and $2.9 \mathrm{Mw}$. This result occurred in a time relatively close time to the predicted occurrence time. Taking this result into account, it was possible to directly observe that the events that occurred were divided into several events of reduced magnitude. It was also observed in this experiment that the time that occurred until the occurrence of the events, fluctuated in approximately 20 minutes of difference between the predicted time and the manifested seismic event time. 


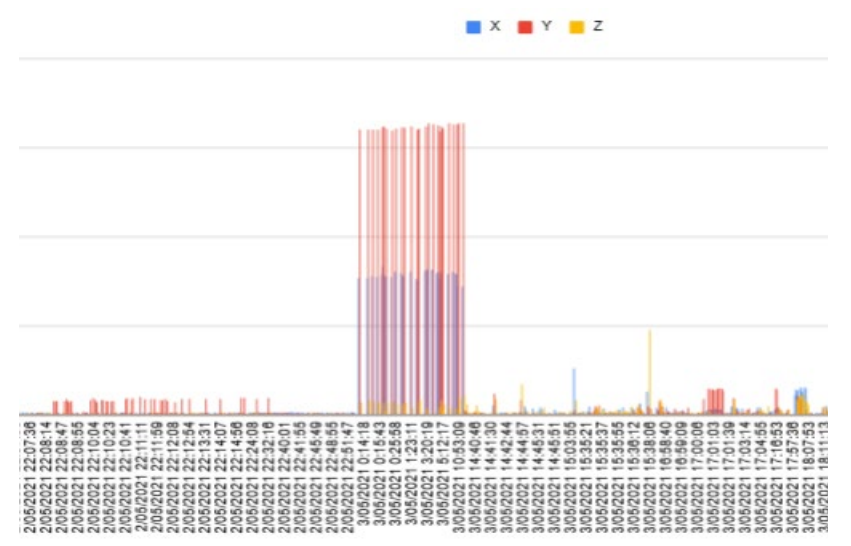

Figure 3. Graph of the Data Recorded During the Anomaly Occurred on May 5, 2021, at San Sebastián Smartphone

On May 3, information from San Sebastián detection smartphone was registered as a new anomaly in the magnetic field. The predicted information was received, and the seismic event was manifested on May 22, 2021, with a difference in time of approximately 20 minutes. In Fig. 3 we can see the graph generated by the information received in the table of data collected by the central data bank in which a notable change is observed in the records of magnetic fields during that day.

\section{Summary and Conclusion}

There are several studies that demonstrate the direct relationship between anomalies in the terrestrial magnetic field and their relationship to future seismic eventualities (Included in the Reference Section). This work focused on developing a network technology through an application for smart phones. Through the magnetometer provided in the smart phones, it was possible to study specific areas of the Island of Puerto Rico where seismic activity is high risk.

Also, its investigation implements as a theory, the empirical equations which was presented in Equations (1) to (5), because have been experimentally developed and demonstrated as initial formulas for the seismic forecast.

Because there is a lot of electromagnetic noise in the environment with the development of the application for smart phones, much of the noise could be removed and it was filtered accurately. In order to isolate electromagnetic noise, the application also incorporated the use of the digital compass. This allowed us to observe that when the magnetic north was deflected, the seismic events tended to occur in the direction of the deflection with respect to the magnetic north. The deflection of the magnetic north occurred for short intervals of time and the more the magnetic north was deflected, the magnitude of the seismic events tended to increase in the study area.

In this research it is proposed as a theory the fact that by using the technology provided by smart phones it is possible to study a seismic region and achieve an early warning of an important seismic event days before the earthquake event. Also, it was demonstrated that through this initiative it is possible to study more regions around the planet in order to save lives and property by being prevented from a dangerous seismic event. This technology in the future could be complemented with specialized laboratory magnetometers that, in combination with smart phones, will increase the accuracy of early detection of earthquakes in a specific geographical area of the planet.

With this work we have begun the initial part of research and implementation of a network monitoring system, now we are working to strengthen the network with more intelligent devices in differen parts of the Planet in order to achieve the most important thing, save Lives in the future.

\section{Nomenclature}

Seismic Precursor: Environmental, biological or planetary energy indicator capable of identifying a trend of seismic risk prior to its occurrence.

Electromagnetic Noise: Noise caused by the different sources of space, natural and artificial energy occurring in the external or internal environment of the Earth.

Magnetic North Deflection: Momentary deviation of the true terrestrial magnetic field, caused by a significant change in energy in a certain geographical area because of the natural interaction between Tectonic Plates.

Algorithm: Programming logic expression developed in a specific programming language for a particular operating system, in this study the Android programming language was used.

$\mathrm{X}, \mathrm{Y}$, and $\mathrm{Z}$ : The vectorial detected magnetic field anomaly obtained in microtesla Units.

M: Magnitude of the earthquake in units Mw or seismic moment. Is also the maximum obtained value from $\mathrm{Mx}, \mathrm{My}$ and $\mathrm{Mz}$ which are presented in Eq. (1), Eq. (2), and Eq. (3).

Time: Approximate time in which the seismic event could occur according to the empirical equation developed for this study.

\section{Declaration of Conflict of Interests}

The authors declare that there is no conflict of interest. They have no known competing financial interests or personal relationships that could have appeared to influence the work reported in this paper.

\section{References}

[1.] Cordaro, E. G. (2018). Latitudinal variation rate of geomagnetic cutoff rigidity in. European Geosciences Union, 1-11.

[2.] Freund, F. (2001, December 12). NASA. NASA Ames Research Center, Moffett Field, Calif.: https://www.nasa.gov/centers/ames/spanish/news/releases/200 1/01_100AR-span.html adresinden alind

[3.] Freund, F. (2011). Pre-earthquake signals: Underlying physical processes. Journal of Asian Earth Sciences 41, 383-400.

[4.] Odenward, S. (2021). Can Smartphones Detect Geomagnetic Storms. AGU Advancing Earth and Space Science, 1-34.

[5.] G. M. Lucas, J. J. (2020). A 100-year Geoelectric Hazard Analysis for the U.S. High-Voltage Power Grid. AGU Advancing Earth and Space Science, 1-15.

[6.] SEISMOLOGICAL SOCIETY OF AMERICA. (2018). Satellite-based earthquake early warning system tested against Chilean great quakes. EureKAlert, 1-2.

[7.] E. M. Takla, K. Yumoto, J. Y. Liu, Y. Kakinami, T. Uozumi, S. Abe, A. Ikeda., Anomalous Geomagnetic Variations Possibly Linked with the Taiwan Earthquake $(\mathrm{Mw}=6.4)$ on December 2009, International Journal of Geophysics, vol. 2011, p. 10, 2011.

[8.] Katsumi Hattoril, ULF Geomagnetic Changes Associated with Large Earthquakes, TAO, vol. 15, no. 3, pp. 329-360, 2004 
[9.] HERAUD, J. A.; CENTA, V. A.; Bleier, T. y Dunson, C., NH22A03 Determining Future Epicenters by Triangulations of Magnetometer Pulses in Peru, American Geophysical Union,AGU, 2013.

[10.] HERAUD, J. A.; CENTA, V. A.; Bleier, T. y Dunson, C., Observation of EM Precursors of Earthquakes from Magnetometers and EQLs, SCEC-SCEP Workshop on Testing External Forecasts and Prediction, Los Angeles, 2013.

[11.] Bleier, T.; Papadopoulos, G.; Dunson, C.; Roth, S.; HERAUD, J. A.; Lira, A.; Freund, F.; Dahlgren, R.; Bambery, R. y Liu, J. Y., Ground Based and Space-Base Electromagnetic Monitoring for PreEarthquake Signals, Earthquake Prediction Studies: Seismic Electromagnetics, pp. 113-127, 2013.

[12.] Ducson, C.; Bleier, T.; HERAUD, J.A.; Muller, S; Lindholm, C; Christman, L.; King, R. y Lemon, J., NH22-01 Electromagnetic Signals and Earthquakes 2.0: Increasing Signal and Reducing Noise, American Geophysical Union-Fall Meeting, San Francisco, California: AGU, 2013.

[13.] J. N. Thomas, J. J. Love, A. Komjathy, O. P. Verkhoglyadova, M Butala, N. Rivera, On the reported ionospheric precursor of the 1999 Hector Mine, California earthquake, Geophysical Research Letters, no. doi: 10.1029/2012GL051022, 2012.

[14.] Cordaro, E. G., Venegas, P., and Laroze, D.: Latitudinal variation rate of geomagnetic cutoff rigidity in the active Chilean convergent margin, Ann. Geophys., 36, 275-285, https://doi.org/10.5194/angeo-36-275-2018, 2018.

[15.] Venegas-Aravena, P., Cordaro, E. G., and Laroze, D.: A review and upgrade of the lithospheric dynamics in context of the seismoelectromagnetic theory, Nat. Hazards Earth Syst. Sci., 19, 16391651, https://doi.org/10.5194/nhess-19-1639-2019, 2019.

\section{How to Cite This Article}

Rosa, R., Ramos, R.A., and Díaz, J.G., Technology for Location, Analysis and Interpretation of Magnetic Alterations as Precursors of Seismic Phenomena Update, Civil Engineering Beyond Limits, 4(2021), 17-21. https://doi.org/10.36937/cebel.2021.004.004 